\title{
Knock-Down of a Tonoplast Localized Low-Affinity Nitrate Transporter OsNPF7.2 Affects Rice Growth under High Nitrate Supply
}

\begin{abstract}
Rui Hu ${ }^{1,2+}$, Diyang Qiu' ${ }^{1,2+}$, Yi Chen ${ }^{3}$, Anthony J. Miller ${ }^{3}$, Xiaorong Fan ${ }^{4}$, Xiaoping Pan ${ }^{1}$ and Mingyong Zhang ${ }^{1 *}$

${ }^{1}$ Key Laboratory of South China Agricultural Plant Molecular Analysis and Genetic Improvement and Guangdong Provincial Key Laboratory of Applied Botany, South China Botanical Garden, Chinese Academy of Sciences, Guangzhou, China, ${ }^{2}$ University of Chinese Academy of Sciences, Beijing, China, ${ }^{3}$ Metabolic Biology Department, John Innes Centre, Norwich, UK, ${ }^{4}$ State Key Laboratory of Crop Genetics and Germplasm Enhancement, Nanjing Agricultural University, Nanjing, China
\end{abstract}

OPEN ACCESS

Edited by:

Sebastien Thomine,

Centre National de la Recherche

Scientifique, France

Reviewed by:

Lixing Yuan,

China Agricultural University, China

Sophie Leran,

New York University, USA

Sylvie Ferrario,

Institut National de la Recherche

Agronomique, France

*Correspondence:

Mingyong Zhang

zhangmy@scbg.ac.cn

tThese authors have contributed equally to this work.

Specialty section:

This article was submitted to

Plant Nutrition,

a section of the journal

Frontiers in Plant Science

Received: 22 July 2016 Accepted: 29 September 2016

Published: 25 October 2016

Citation:

Hu R, Qiu D, Chen Y, Miller AJ,

Fan X, Pan X and Zhang M (2016) Knock-Down of a Tonoplast Localized

Low-Affinity Nitrate Transporter OsNPF7.2 Affects Rice Growth under

High Nitrate Supply.

Front. Plant Sci. 7:1529.

doi: 10.3389/fpls.2016.01529
The large nitrate transporter 1/peptide transporter family (NPF) has been shown to transport diverse substrates, including nitrate, amino acids, peptides, phytohormones, and glucosinolates. However, the rice (Oryza sativa) root-specific family member OsNPF7.2 has not been functionally characterized. Here, our data show that OsNPF7.2 is a tonoplast localized low-affinity nitrate transporter, that affects rice growth under high nitrate supply. Expression analysis showed that OsNPF7.2 was mainly expressed in the elongation and maturation zones of roots, especially in the root sclerenchyma, cortex and stele. It was also induced by high concentrations of nitrate. Subcellular localization analysis showed that OsNPF7.2 was localized on the tonoplast of large and small vacuoles. Heterologous expression in Xenopus laevis oocytes suggested that OsNPF7.2 was a low-affinity nitrate transporter. Knock-down of OsNPF7.2 retarded rice growth under high concentrations of nitrate. Therefore, we deduce that OsNPF7.2 plays a role in intracellular allocation of nitrate in roots, and thus influences rice growth under high nitrate supply.

\section{Keywords: OsNPF7.2, nitrate, transporter, growth, Oryza sativa}

\section{INTRODUCTION}

Nitrogen $(\mathrm{N})$ is one of the most important macro elements in plants, essential for growth and development. Most plants need to uptake $\mathrm{N}$ through their roots from the soil. In agriculture, crops are generally fertilized with large amounts of $\mathrm{N}$ to obtain high yields, even though more than half of the $\mathrm{N}$ added to cropland can be lost to the environment (Lassaletta et al., 2014). Therefore, it is important to study the uptake, transport and assimilation of $\mathrm{N}$ for effective fertilizer management practices. $\mathrm{N}$ as a fertilizer is acquired mainly in the form of ammonium and nitrate by roots (Xu et al., 2012). The nitrate taken up from the rhizosphere is reduced to nitrite in the plant, which is then further reduced to ammonium.

Abbreviations: CDS, coding DNA sequence; GFP, green fluorescent protein; GUS, $\beta$-glucuronidase; MBS, modified Barth's saline; MCS, multi cloning site; N, nitrogen; NPF, NRT1/PTR family; NRT, nitrate transporter; qPCR, real-time quantitative polymerase chain reaction; UTR, untranslated region; WT1, wild type variety Zhonghua 11; WT2, wild type variety Hwayoung. 
Ammonium is then subsequently assimilated to glutamine, and further to glutamic acid and other forms of organic $\mathrm{N}$.

Nitrate and ammonium can be used as the major $\mathrm{N}$ sources of rice (Kronzucker et al., 1999). After uptake from the soil, only $37 \%$ of incoming nitrate and $24 \%$ of incoming ammonium can be translocated to shoot. However, $52-53 \%$ of the $\mathrm{N}$ absorbed can be assimilated and compartmentalized to the vacuole in rice (Kronzucker et al., 2000). Therefore, the vacuole plays an important role in efficient $\mathrm{N}$ utilization in rice.

The nitrate transporter 1/peptide transporter family (NPF, also known as the NRT1 family) is related to the SLC15/PepT/PTR/POT family of peptide transporters in animals (Léran et al., 2014). In plants, the reported members of the NPF can transport not only peptides, but also nitrate, nitrite, amino acids, phytohormones and glucosinolates (Zhou et al., 1998; Tegeder and Rentsch, 2010; Kanno et al., 2012; Nour-Eldin et al., 2012; Léran et al., 2014; Pike et al., 2014). It is worth mentioning here that many members of this family have exhibited nitrate transport activity (Léran et al., 2014).

The mechanism of nitrate transport and function of some NPFs has been investigated in Arabidopsis. Unlike the highaffinity nitrate transporter family (NRT2 family), the NRTs of the NPF with the exception of AtNPF6.3, are low-affinity NRTs. Previously known as AtCHL1 or AtNRT1.1, AtNPF6.3 is a dualaffinity NRT (Liu et al., 1999), and was first reported as a nitrateinducible plant NRT (Tsay et al., 1993). Later, it was ascertained to be a nitrate sensor (Ho et al., 2009), which changed auxin distribution in response to different nitrate conditions to module the root structure (Krouk et al., 2010). It was also found that calcium acted as downstream signal of AtNPF6.3 (Riveras et al., 2015). The crystal structure of the AtNPF6.3 protein has been described (Parker and Newstead, 2014; Sun et al., 2014). Apart from AtNPF6.3, Arabidopsis is also known to have many NPFs nitrate transporter to facilitate a multitude of functions.

Unlike Arabidopsis, few rice NPF genes have been investigated. OsNPF8.9 (OsNRT1) was reported as a NRT after expression in Xenopus oocytes (Lin et al., 2000). The role of OsNPF4.1 (SP1) has been demonstrated in the rice panicle elongation ( $\mathrm{Li}$ et al., 2009) and the overexpression of OsNPF8.20 (OsPTR9) improved $\mathrm{N}$ utilization efficiency, growth and grain yield (Fang et al., 2013). However, the transported substrates of OsNPF4.1 and OsNPF8.20 remain unknown. OsNPF6.5 (OsNRT1.1B) showed dual-affinity nitrate transport activity, and it diverged between indica and japonica rice cultivars during evolution. The OsNPF6.5-indica variation had enhanced $\mathrm{N}$ use efficiency (Hu et al., 2015). In addition, two NRTs, OsNPF2.4 (Xia et al., 2015) and OsNPF2.2 ( $\mathrm{Li}$ et al., 2015), participated in long distance root-to-shoot nitrate transport. Knockout of OsNPF2.4 impaired potassium $(\mathrm{K})$-coupled nitrate upward transport and nitrate-redistribution from old leaves to $\mathrm{N}$-starved roots and young leaves. Moreover, knockout of OsNPF2.4 increased the shoot: root ratio of tissue $\mathrm{K}$ under higher nitrate (Xia et al., 2015).

To secure their $\mathrm{N}$ supply, plants have multiple transport systems for $\mathrm{N}$ uptake from the soil as well as for intra- and intercellular reallocation of $\mathrm{N}$ containing compounds. Vacuole compartmentation is an important part of nitrate utilization at intracellular level. Nitrate is imported into vacuoles under conditions of abundant nitrate outside, and exported to cytosol to meet subsequently nitrate deficiency in the environment. Several fold more nitrate was measured in vacuoles than cytosol (Martinoia et al., 1981; van der Leij et al., 1998). Plants need active transporters to overcome the concentration gradient between vacuoles and cytosol. However, the transporters on the vacuolar membrane for this function are rarely described. A chloride channel (CLC) protein family member AtCLCa was reported as a vacuolar nitrate/proton antiporter in Arabidopsis (De Angeli et al., 2006). The NRT2 family member AtNRT2.7 was found to be localized on tonoplast and facilitated nitrate accumulation in the seed (Chopin et al., 2007).

Many NPFs localized on the plasma membrane mediate intercellular allocation of nitrate, but little is known about intracellular nitrate transport. Only a few members of NPF were found to be localized to intracellular membranes. For example, AtPTR2, AtPTR4 and AtPTR6 were localized at the tonoplast (Weichert et al., 2012). AtPTR2 was shown to be a peptide transporter, but the function of AtPTR4 and AtPTR6 was not clear. AtNPF3.1, a nitrate/nitrite transporter (Pike et al., 2014) and GA influx carrier cross cell membranes, was localized at the plasma membrane and displayed intracellular membrane compartment localization (Tal et al., 2016). The cucumber nitrite transporter CsNPF3.2 (CsNitr1-L) was localized on the chloroplast (Sugiura et al., 2007). Here, we characterized a tonoplast localized member of the rice NPF family.

On analysis of a public expression database RiceXPro ${ }^{1}$, OsNPF7.2 was found to be mainly expressed in roots, this was verified by our qPCR and GUS staining of promoterGUS transgenic rice. Heterologous expression in Xenopus laevis oocytes suggested that OsNPF7.2 is a low-affinity NRT. OsNPF7.2 was localized on the membrane of large and small vacuoles. Knock-down of OsNPF7.2 caused rice growth retardation under high nitrate supply. Our results suggest OsNPF7.2 plays an important role in nitrate accumulation and homeostasis in rice.

\section{MATERIALS AND METHODS}

\section{Plant Materials and Growth Conditions}

The rice cultivar used in this study was the japonica rice variety Zhonghua 11 (ZH11), except for the special annotation. The hydroponic experiments were conducted using the modified rice nutrient solution of the International Rice Research Institute (IRRI solution contains $1.43 \mathrm{mM} \mathrm{NH}_{4} \mathrm{NO}_{3}, 0.32 \mathrm{mM} \mathrm{NaH}_{2} \mathrm{PO}_{4}$, $0.51 \mathrm{mM} \mathrm{K}_{2} \mathrm{SO}_{4}, 1 \mathrm{mM} \mathrm{CaCl}_{2}, 1.65 \mathrm{mM} \mathrm{MgSO}_{4}, 8.9 \mu \mathrm{M} \mathrm{MnSO}_{4}$, $0.5 \mu \mathrm{M} \mathrm{Na}_{2} \mathrm{MoO}_{4}, 18.4 \mu \mathrm{M} \mathrm{H}_{3} \mathrm{BO}_{3}, 0.14 \mu \mathrm{M} \mathrm{ZnSO}_{4}, 0.16 \mu \mathrm{M}$ $\mathrm{CuSO}_{4}, 40 \mu \mathrm{M} \mathrm{FeSO}_{4}$ ) at ambient conditions of $28^{\circ} \mathrm{C}, 14 \mathrm{~h}$ light, $10 \mathrm{~h}$ dark (Yoshida et al., 1976). For growth in 1/2 MS (Murashige and Skoog, 1962) medium, seeds were sterilized with 5\% sodium hypochlorite solution then washed with water. For the various treatments, the $\mathrm{N}$ source of the IRRI solution or $1 / 2 \mathrm{MS}$ was changed.

\footnotetext{
${ }^{1}$ http://ricexpro.dna.affrc.go.jp/
} 
For short-term induction experiments, ZH11 plants were germinated in sterile conditions, and then grown on the IRRI solution for 2 weeks. Before treatment, the plants were transferred for a 3-day nitrate-starvation, in which $\left(\mathrm{NH}_{4}\right)_{2} \mathrm{SO}_{4}$ served as sole $\mathrm{N}$ source, and then placed in the IRRI solution substituted with high and low concentrations of $\mathrm{KNO}_{3}$ as the $\mathrm{N}$ supply. The IRRI solution containing $\mathrm{KCl}$ (no $\mathrm{N}$ ) was used as control. For long-term expression analysis, plants were grown on $1 / 2 \mathrm{MS}$ medium containing different concentrations of $\mathrm{KNO}_{3}$ for 2 weeks. In the long-term experiment, ammonium was used to maintain the total $\mathrm{N}$ concentrations equal in the medium.

\section{Real-Time PCR}

Total RNA was isolated using RNAiso Plus following the manufacturer's instructions (Takara, Japan). The synthesis of cDNA was carried out using the Takara Reverse Transcriptase M-MLV (RNase H-) (Takara, Japan). The qPCR was performed to monitor gene expression, and UBC (LOC_Os02g42314.2) (Jain et al., 2006) was used as the reference. The procedure (qPCR) was carried out in the presence of the double-strand DNA-specific dye SYBR Green I (SYBR ${ }^{\circledR}$ Premix Ex Taq GC Takara, Japan) and monitored in real time with the Roche LightCycler 480 system (Roche, Switzerland). Semi-quantitative PCR was implemented using OseEF-1 $\alpha$ (LOC_Os03g08010.1, or LOC_Os03g08020.1) as reference.

\section{Vectors Construct}

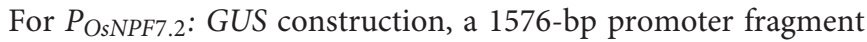
containing the $5^{\prime}$ UTR of OsNPF7.2 was amplified by PCR. Then this fragment was inserted into the clone vector $p G E M-T$ Easy (Promega, China). Subsequently, the fragment was sequenced at Invitrogen (China). The sequenced fragment was then inserted into pCambia1301 to replace the $35 S$ promoter via SacI and NcoI. Primers are listed in Supplementary Table S1. For RNAi construction, the vector pTCK303 (Wang et al., 2004) was used. To avoid disturbing other homologous genes, 122-bp 5' UTR of OsNPF7.2 was used as the OsNPF7.2-RNAi fragment. The 122bp fragment in $5^{\prime}$ UTR of OsNPF7.2 was cloned to pTCK303 by BamHI and KpnI for the sense strand, and SpeI and SacI for the antisense strand.

\section{Transformation of Rice}

The constructs were introduced into the Agrobacterium tumefaciens strain EHA105. Then the japonica rice (Oryza sativa L.) variety $\mathrm{ZH} 11$ was transformed with the Agrobacteriummediated transformation method as previously described (Hiei et al., 1997).

\section{Subcellular Localization}

For 35S: OsNPF7.2: EGFP construction, the EGFP was introduced into the BiFC vector $p S A T 1 A-n E Y F P-N 1$ (Li et al., 2014) to replace $n E Y F P$ via $X b a \mathrm{I}$ and $K p n \mathrm{I}$, then the CDS without stop codon of OsNPF7.2 was cloned into the vector via XhoI and EcoRI. Moreover, a linker (GGGS) 2 was inserted between the CDS of OsNPF7.2 and EGFP. Rice protoplasts were isolated and transformed by using a previously described protocol (Zhang et al., 2011). The transformed protoplasts were observed with confocal laser scanning microscope (Leica TCS SP5, Germany) with $488 \mathrm{~nm}$ exciting wavelength for GFP and $543 \mathrm{~nm}$ exciting wavelength for mCherry. The images were coded green for GFP and red for mCherry.

\section{Histochemical Analysis and Section}

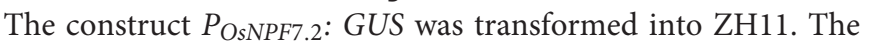
transgenic P OsNPF7.2: GUS rice seeds were sown on 1/2 MS medium. The GUS stain was performed for $4 \mathrm{~h}$ except special annotation with $0.5 \mathrm{mg} \mathrm{mL}^{-1} \mathrm{X}$-Gluc (5-bromo-4-chloro-3indolyl- $\beta$-D-glucuronide), $3 \mathrm{mM} \mathrm{K}_{4} \mathrm{Fe}(\mathrm{CN})_{6}, 3 \mathrm{mM} \mathrm{K}_{3} \mathrm{Fe}(\mathrm{CN})_{6}$, $0.05 \%$ Triton X-100, and $100 \mathrm{mM} \mathrm{Na} 2 \mathrm{HPO}_{4}-\mathrm{NaH}_{2} \mathrm{PO}_{4}, \mathrm{pH}$ 7.0. The reaction was stopped by $70 \%$ ethanol. After staining, tissues were fixed in a glutaraldehyde solution at $4^{\circ} \mathrm{C}$, and embedded in Spurr's resin. The samples were sectioned into $3 \mu \mathrm{m}$ thickness and observed under the microscope (ZISS AXOPLAN2, Germany).

\section{Functional Analysis of OsNPF7.2 in Xenopus laevis Oocytes}

The pT7TS (Cleaver et al., 1996) was used as the backbone for all the Xenopus oocytes expression vectors. For $p$ T7TS-OsNPF7.2 and pT7TS-AtNPF6.3, the CDS of OsNPF7.2 or AtNPF6.3 was inserted separately into the backbone via BglII and SpeI.

The nitrate transport activity of OsNPF7.2 was measured as described previously (Tong et al., 2005) with some modification. Briefly, the CDS of OsNPF7.2 and AtNPF6.3 were cloned into the $X$. laevis oocytes expression vector pT7TS. Capped mRNA (cRNA) was transcribed in vitro using mMESSAGE mMACHINE T7 kits (Ambion, USA) following the manufacturer's instructions. Fifty nano liters of $1 \mu \mathrm{g} \mathrm{LL}^{-1} \mathrm{cRNA}$ was injected in each oocyte and the oocytes were incubated in nitrate-free MBS (modified Barth's saline) for 2 days before treatment. For uptake, the oocytes were exposed overnight to $10 \mathrm{mM}$ or $200 \mu \mathrm{M}$ of $\mathrm{Na}^{15} \mathrm{NO}_{3}$ in nitrate-free MBS. For efflux, oocytes were injected with $50 \mathrm{~nL}$ of $20 \mathrm{mM} \mathrm{Na}{ }^{15} \mathrm{NO}_{3}$ and further incubated in nitrate-free MBS ( $\mathrm{pH} 7.5$ ) for 8 or 24 h respectively. After treatment the oocytes were all washed 6 times with $\mathrm{NO}_{3}^{-}$ free MBS and dried for 3 days at $70^{\circ} \mathrm{C}$. The content of ${ }^{15} \mathrm{~N}$ was analyzed using an isotope ratio mass spectrometer coupled with $\mathrm{N}$ elemental analyzer (IsoPrime100, Elemental Scientific, USA).

\section{RESULTS}

\section{OsNPF7.2 Is Mainly Expressed in Elongation and Maturation Zones of Roots}

Microarray data analysis showed that OsNPF7.2 was mainly expressed in the elongation and maturation zones of roots at the vegetative stage as shown in the Rice Expression Profile Database $\left(\right.$ RiceXPro $^{2}$ ) (Supplementary Figures S1A,B). The qPCR analysis verified that OsNPF7.2 was mainly expressed in the roots of

${ }^{2}$ http://ricexpro.dna.affrc.go.jp/ 


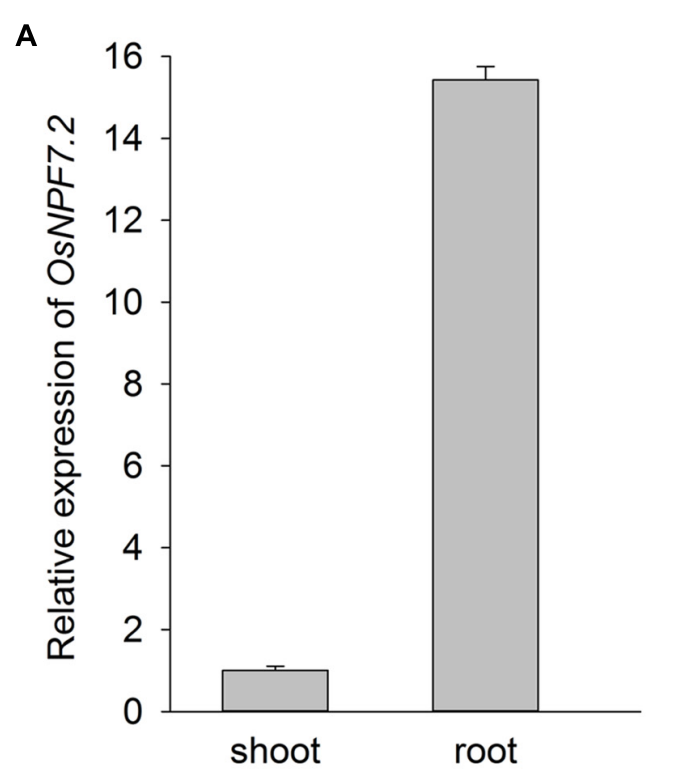

B

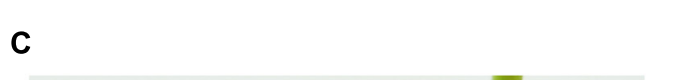

\section{D}
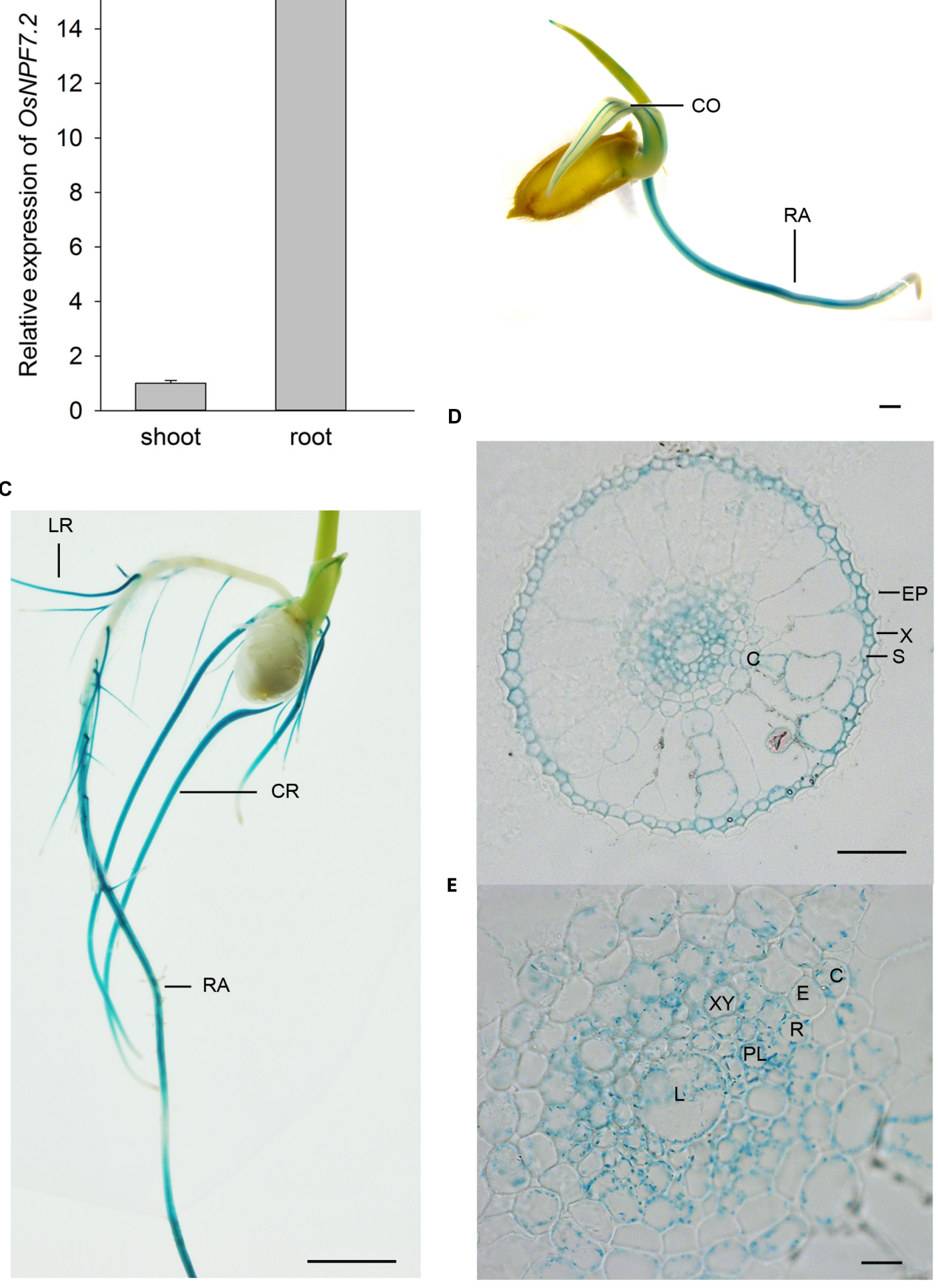

E

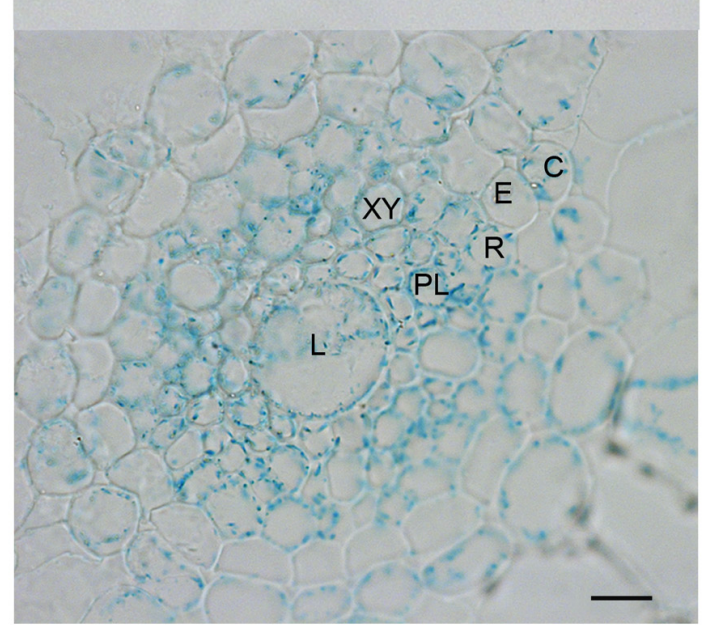

FIGURE 1 | OSNPF7.2 is mainly expressed in the elongation and maturation zones of roots. (A) qPCR analysis of OsNPF7.2 expression in 5-day-old rice seedlings. UBC was used as reference gene. Data represent mean $\pm S D$ from one experiment of six seedlings, three independent experiments showed the same result. (B-E) GUS staining of $P_{\text {OSNPF7.2: }}$ GUS seedlings. GUS staining of whole plant (B), roots (C), and cross section of roots (D,E). Bar $=1 \mathrm{~mm}$ in (B), $3 \mathrm{~mm}$ in (C), $20 \mu \mathrm{m}$ in (D) and $10 \mu \mathrm{m}$ in (E). CO, coleoptile; RA, radical root; CR, crown root; LR, lateral root; EP, epidermis; X, exodermis; S, sclerenchyma; C, cortex; E, endodermis; R, pericycle; $\mathrm{XY}$, xylem; PL, phloem; L, late metaxylem. 
seedlings (Figure 1A). To elucidate a more detailed expression pattern of OsNPF7.2, the $1.5-\mathrm{kb}$ upstream region of its CDS was used to drive the expression of GUS. The GUS staining analysis further confirmed that OsNPF7.2 was mainly expressed in the elongation and maturation zones of roots, and in coleoptile of seedlings (Figures 1B,C). A weak GUS staining was also detected in the major veins of the leaves (Supplementary Figure S1C). The cross sections showed that OsNPF7.2 was mainly expressed in the root sclerenchyma, cortex and stele (Figures 1D,E). The lateral root primordium was not stained (Supplementary Figure S1D). The data thus suggests that OsNPF7.2 mainly functions in the roots.

\section{High Nitrate Induces OsNPF7.2 Expression}

Although a number of Arabidopsis NPF members have been demonstrated to transport different types of substrates, including nitrate, amino acids, oligopeptides, phytohormones and glucosinolates, OsNPF7.2 appears to be the most homologous with two NRTs AtNPF7.2 (AtNRT1.8) (Li et al., 2010) and AtNPF7.3 (AtNRT1.5) (Lin et al., 2008). Therefore, the response of OsNPF7.2 expression in roots to nitrate was tested using qPCR. In the experiment on shifting from a nitrate starved solution to $10 \mathrm{mM}$ nitrate solution, the OsNPF7.2 mRNA level in rice roots increased more than 18 -fold within $1 \mathrm{~h}$, and subsequently showed a rapid decline. The level in $\mathrm{KCl}$ control also increased 5-fold within $1 \mathrm{~h}$ (Figure 2A). In $0.5 \mathrm{mM}$ nitrate induction, OsNPF7.2 mRNA level in roots only increased 5fold within $0.5 \mathrm{~h}$, while that in $\mathrm{KCl}$ control also increased 5-fold within $0.5 \mathrm{~h}$ (Figure 2B). To observe the long-term induction (Figure 2C), plants were grown on 1/2 MS medium (Murashige and Skoog, 1962) containing different concentrations of $\mathrm{KNO}_{3}$ for 2 weeks. Ammonium was used in the media to maintain the total $\mathrm{N}$ concentrations. The expression of OsNPF7.2 in roots in high concentrations of nitrate (10 and $20 \mathrm{mM}$ ) was significantly higher than that in low concentrations of nitrate $(0-1 \mathrm{mM})$ (Figure $2 \mathrm{C}$ ). The data therefore indicates that high concentrations of nitrate induce the expression of OsNPF7.2.

\section{OsNPF7.2 Is Localized on Tonoplast}

Members of NPF family have been shown to be localized on the plasma membrane or tonoplast. To determine subcellular localization of OsNPF7.2, the enhanced green fluorescent protein (EGFP) fused to $\mathrm{N}$ - or C-terminal of OsNPF7.2 was transiently expressed in rice protoplasts. The EGFP fluorescence signal of OsNPF7.2: EGFP (Figure 3C) and EGFP: OsNPF7.2 (Figure 3G) partially co-localized with the mCherry fluorescence signal (Figures 3D,H) of the tonoplast marker $\gamma$-TIP: mCherry (vac$r k$ ) (Nelson et al., 2007), while free EGFP showed the whole cell fluorescence (Figures 3A,B). However, bright small vacuolar structures could also be seen and did not merge with the marker, as the arrows indicated in Figures 3C,G. $\gamma$-TIP not only marks lytic vacuoles, but also marks protein storage vacuoles and vacuoles storing vegetative storage proteins and pigments (Jauh et al., 1999). Thus the partially localization

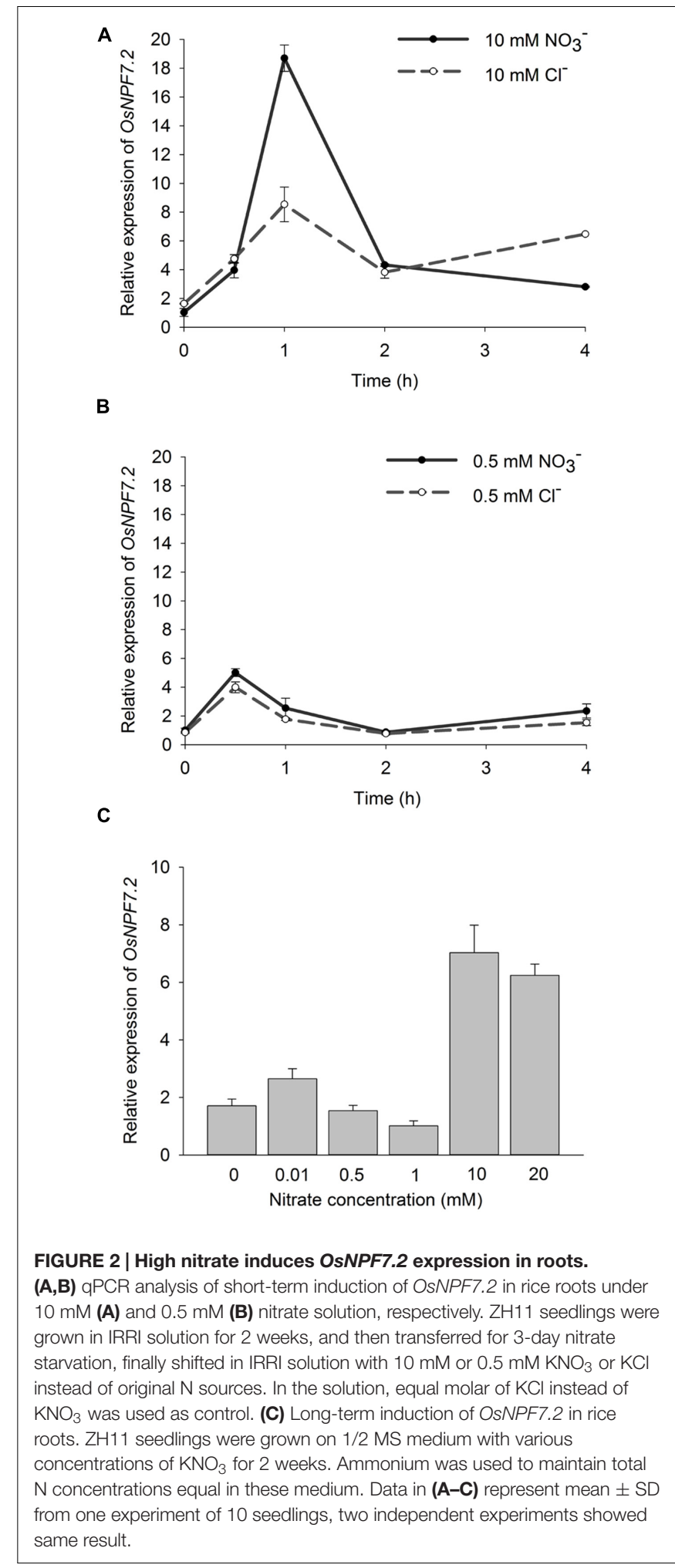

of OsNPF7.2 with $\gamma$-TIP indicates that OsNPF7.2 may be localized not only on the tonoplast of known types of vacuoles, but also to other kinds of vacuole. A partial co-localization of OsNPF7.2 with a rice lytic vacuole membrane protein 


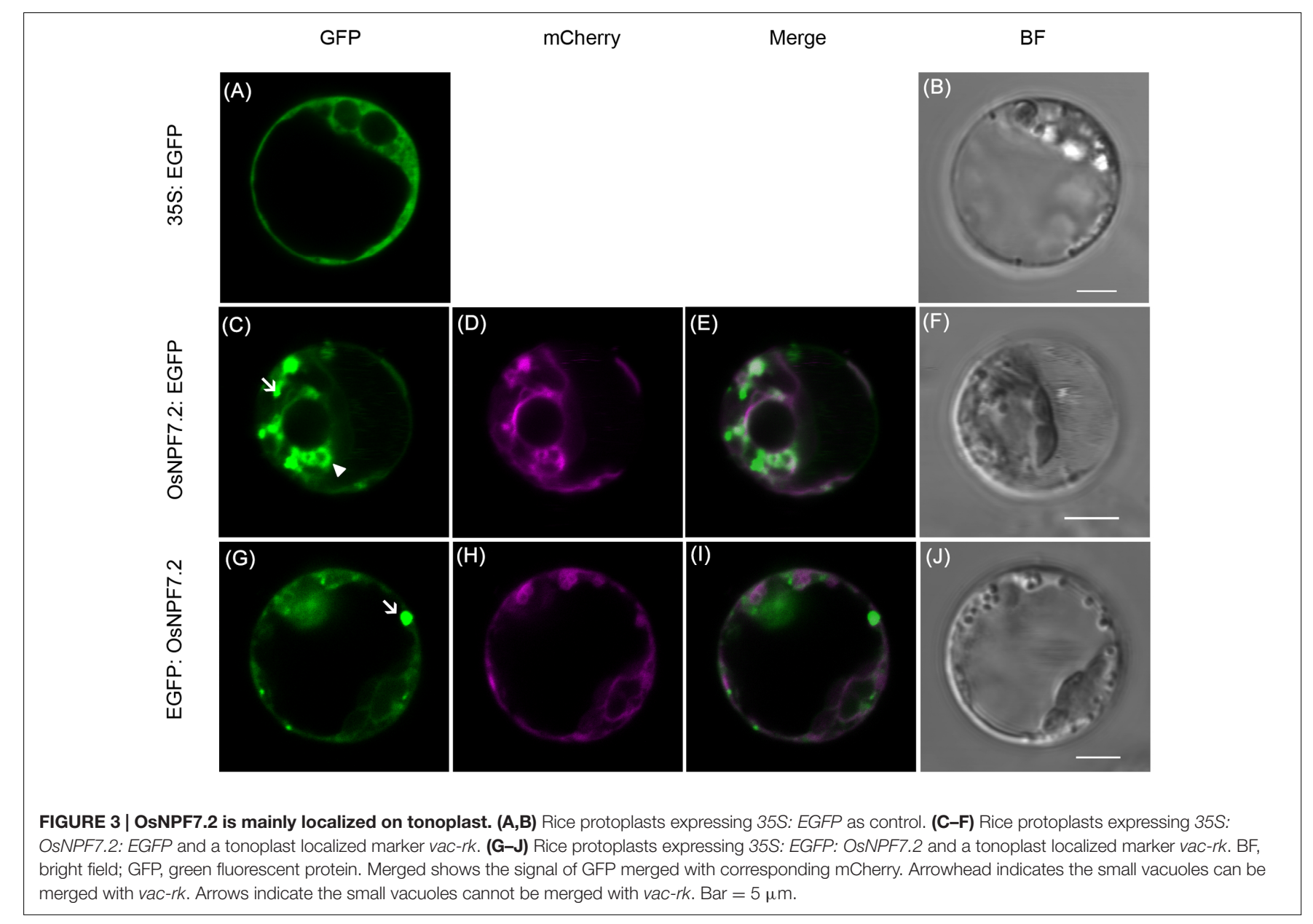

OsTPKa (Isayenkov et al., 2011) also suggested OsNPF7.2 localized on tonoplast (Supplementary Figure S2A). To further confirm the localization of OsNPF7.2 in situ, we constructed 35S:OsNPF7.2:EGFP transgenic rice to observe the localization of OsNPF7.2 in root cells. As shown in Supplementary Figure S2B, the fluorescence signal distributed at small vacuolar structures beside a larger vacuole. The fluorescence of free EGFP (35S: EGFP) could be seen in the cytoplasm and nucleus, but it did not show obvious fluorescence in the small vacuolar structure. These results imply that OsNPF7.2 is mainly localized on the tonoplast.

\section{OsNPF7.2 Is a Nitrate Transporter}

Four members of the rice NPF family have been demonstrated to be NRTs (Lin et al., 2000; Hu et al., 2015; Li et al., 2015; Xia et al., 2015). We also tested the nitrate transport activity of OsNPF7.2 using the $X$. laevis oocyte expression system. On exposure to $10 \mathrm{mM} \mathrm{Na}{ }^{15} \mathrm{NO}_{3}$ at $\mathrm{pH} 5.5$, the ${ }^{15} \mathrm{NO}_{3}^{-}$ accumulation in OsNPF7.2-injected Xenopus oocytes increased by $67 \%$ compared with the water-injected Xenopus oocytes (Figure 4A). However, at $\mathrm{pH} 7.5$, the ${ }^{15} \mathrm{NO}_{3}^{-}$accumulation of OsNPF7.2-injected Xenopus oocytes increased by $32 \%$ compared with the water-injected Xenopus oocytes. This indicates that OsNPF7.2 is a NRT. However, compared to AtNPF6.3, which showed a pronounced difference in ${ }^{15} \mathrm{~N}$ uptake between $\mathrm{pH} 5.5$ and $\mathrm{pH} 7.5$, nitrate uptake of OsNPF7.2 was less sensitive to the $\mathrm{pH}$ change. At the $200 \mu \mathrm{M} \mathrm{Na}{ }^{15} \mathrm{NO}_{3}$ incubation in $\mathrm{pH}$ 5.5, the dual-affinity NRT AtNPF6.3 showed an expected uptake activity, however, OsNPF7.2 did not show any uptake activity. Taking into account that the reported NRTs of NPF are lowaffinity NRTs (except AtNPF6.3 and OsNPF6.5), the uptake data in Xenopus oocytes suggests that OsNPF7.2 is a low-affinity NRT.

The sorting signal for the tonoplast of Arabidopsis PTRs was reported to be $\mathrm{EX}_{3-5} \mathrm{LL}$ at the $\mathrm{N}$-terminal (Komarova et al., 2012). OsNPF7.2 has the $\mathrm{EX}_{6} \mathrm{LL}$ motif (Supplementary Figure $\mathrm{S} 3 \mathrm{~A})$. We expected that OsNPF7.2 would be targeted to the plasma membrane, by changing the $\mathrm{EX}_{6} \mathrm{LL}$ motif to $\mathrm{EX}_{6} \mathrm{AA}$ or deleting the LL. $\mathrm{Na}^{15} \mathrm{NO}_{3}$ uptake of the mutated proteins was measured, however, mutations of the putative sorting signal had no effect on the uptake in Xenopus oocytes (Supplementary Figure S3B). To investigate whether OsNPF7.2 mediates nitrate efflux, an oocyte efflux measurement was carried out. As shown in Figure 4B, the amount of ${ }^{15} \mathrm{NO}_{3}^{-}$retained in OsNPF7.2-injected Xenopus oocytes was almost the same as water-injected Xenopus oocytes, which is unlike AtNPF6.3 (Leran et al., 2013). The data obtained suggests that OsNPF7.2 is not involved in nitrate efflux in Xenopus oocytes. 


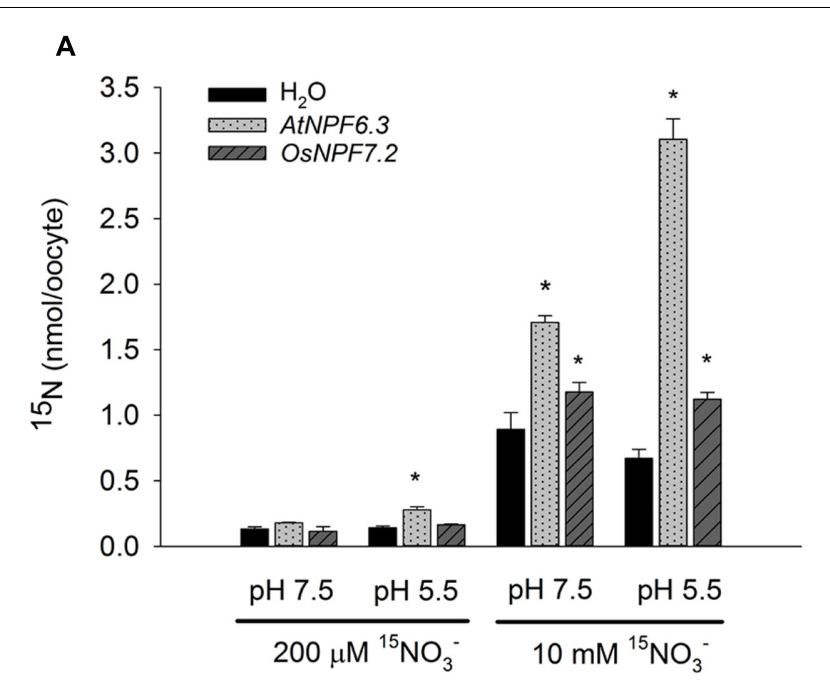

B

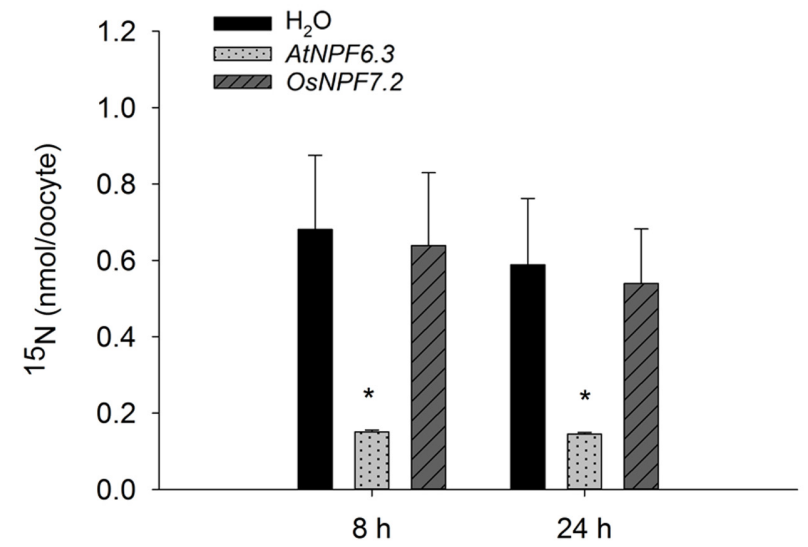

FIGURE 4 | OsNPF7.2 is a low-affinity NRT. (A) Nitrate uptake assay by Xenopus oocytes expression system. (B) Nitrate efflux assay by Xenopus oocytes expression system. AtNPF6.3 was used as positive control. Water-injected Xenopus oocytes were used as negative control. Data represent means of five oocytes and SD. Two independent experiments showed same result. Asterisks upon the bars indicate statistically significant differences $(P<0.05)$ between the $c R N A$-injected Xenopus oocytes and water-injected Xenopus oocytes by $t$-test.

\section{Molecular Analysis of OsNPF7.2 Knock-Down Mutants}

To investigate the function of OsNPF7.2, two mutants of the gene were obtained from RMD (Rice Mutant Database ${ }^{3}$ ) and RISD DB (Rice T-DNA Insertion Sequence Database ${ }^{4}$ ), respectively. The mutant osnpf7.2-1 was generated from ZH11 (WT1) by a retrotransposon Tos17 insertion in the first intron of OsNPF7.2 (Figure 5A) (Zhang et al., 2006). The other mutant, osnpf7.22 was generated from japonica variety Hwayoung (WT2) by T-DNA insertion in the promoter of OsNPF7.2 (Figure 5A)

${ }^{3}$ http://rmd.ncpgr.cn/

${ }^{4}$ http://cbi.khu.ac.kr/RISD_DB.html
A osnpf7.2-2 osnpf7.2-1

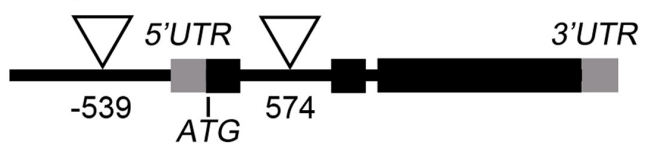

B

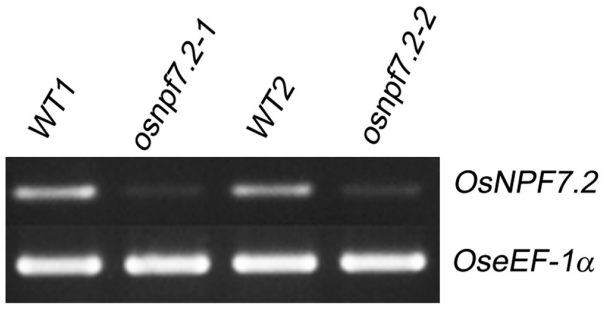

C

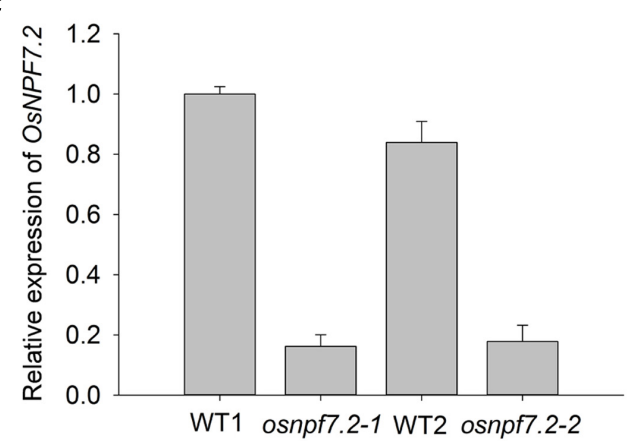

D

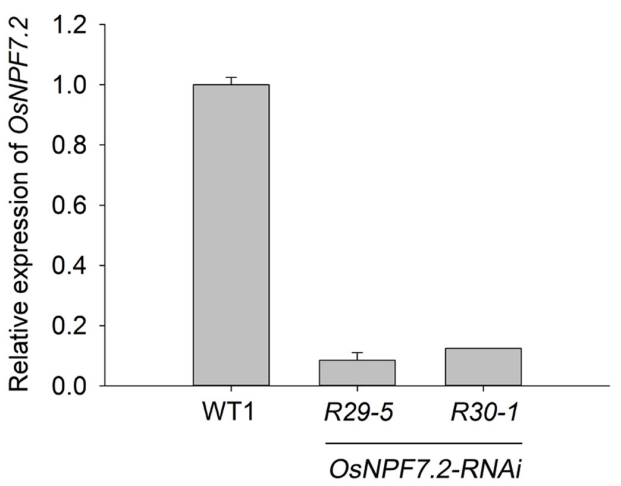

FIGURE 5 | osnpf7.2 mutants and OsNPF7.2-RNAi lines are knock-down lines of OsNPF7.2. (A) Diagram of the insertional positions of retrotransposon Tos17 and T-DNA in two osnpf7.2 mutants. osnpf7.2-1 is inserted by Tos 17, and osnpf7.2-2 is inserted by T-DNA. (B,C) Detection of OsNPF7.2 expression level in two osnpf7.2 mutants with semi-quantitative-PCR (B) and qPCR (C). (D) Detection of OsNPF7.2 expression level in OsNPF7.2-RNAi lines with qPCR. Data of (C,D) represent mean \pm SD from one experiment of 10 seedlings, three independent experiments showed same result.

(Jeong et al., 2006). Flanking sequencing of the PCR fragments verified the insertions in the two mutants. Southern blot analysis showed that osnpf7.2-2 contained one copy of T-DNA insertion (Supplementary Figure S4). The insertion copy number of 
Tos17 inserted in osnpf7.2-1 was not detected, since Tos17 is multicopy retrotransposon in rice and activated by tissue culture (Hirochika, 2001). Semi-quantitative-PCR and qPCR showed that OsNPF7.2 expression in the two osnpf7.2 mutants was decreased, when compared with those of their corresponding wild type (Figures 5B,C). The qPCR primers were based on first and second exon to span the insertion site of osnpf7.2-1. Tos17 was inserted into the intron of OsNPF7.2-1, that might influence the splicing efficiency; therefore, a part of mRNA can be spliced successfully. osnpf7.2-2 was inserted by T-DNA in the promoter of OsNPF7.2, that might influence the efficiency of OsNPF7.2 transcription.

To validate the results from the osnpf7.2 mutants, the RNA interference plants of OsNPF7.2 (OsNPF7.2-RNAi) were generated in ZH11 (WT1) background. Southern blot analysis showed that line 29-5 and line 30-1 of OsNPF7.2-RNAi contained two and one copy(s) of the OsNPF7.2-RNAi fragment, respectively (Supplementary Figure S4). The qPCR result revealed that expression of OsNPF7.2 significantly decreased in these two lines (R29-5 and R30-1) (Figure 5D). They were subsequently used for further analysis.

\section{Knock-Down of OsNPF7.2 Affects Rice Growth under High $\mathrm{NO}_{3}^{-}$Condition}

Because OsNPF7.2 was induced by a high nitrate concentration (Figure 2), the effect of nitrate on growth of the knock-down mutant OsNPF7.2-1 was further investigated (Figure 6). The plants were grown on 1/2 MS medium containing various concentrations of $\mathrm{KNO}_{3}$ for 7 days, and total $\mathrm{N}$ concentrations was maintained with ammonium in the medium. The root length of osnpf7.2-1 decreased 11.3 and $17.6 \%$ on $10 \mathrm{mM}$ and $20 \mathrm{mM}$ nitrate medium compared to WT1. The shoot length of osnpf7.2-1 decreased 29.3 and $42 \%$ on $10 \mathrm{mM}$ and $20 \mathrm{mM}$ nitrate medium, respectively. However, there was no statistically significant difference between osnpf7.2-1 and WT1 under lower nitrate concentrations (Figures 6A,B).

To confirm that the difference in growth is caused by nitrate and not by ammonium, the plants were also grown in a medium containing $10 \mathrm{mM} \mathrm{NH} \mathrm{NO}_{3}$ or $\left(\mathrm{NH}_{4}\right)_{2} \mathrm{SO}_{4}$ as $\mathrm{N}$ source. Length of root and shoot of osnpf7.2-1 decreased 28.8 and $33.3 \%$ than that of WT1, when grown on $\mathrm{NH}_{4} \mathrm{NO}_{3}$ medium, but these differences were not present in plants on $\left(\mathrm{NH}_{4}\right)_{2} \mathrm{SO}_{4}$ medium (Figures 6C-E). This indicates that the growth difference between osnpf7.2-1 and wild type is caused by nitrate.

To further confirm the effects of high nitrate on growth of osnpf7.2 mutants (Figure 6), two OsNPF7.2-RNAi lines as well as osnpf7.2 mutants were grown in IRRI solution containing $10 \mathrm{mM}$ nitrate, $0.5 \mathrm{mM}$ nitrate, and $5 \mathrm{mM} \mathrm{NH}_{4} \mathrm{NO}_{3}$ as $\mathrm{N}$ source. Similar to the osnpf7.2 mutants, the OsNPF7.2-RNAi plants also showed a decrease in fresh weight, compared to their wild type, under high nitrate supply (Figure 7). As shown in Figure 7A, in $0.5 \mathrm{mM} \mathrm{NO}_{3}^{-}$solution, only OsNPF7.2-RNAi 29-5 plants showed a decrease in fresh weight, while all the knock-down lines showed decreased fresh weight in $10 \mathrm{mM}$ $\mathrm{NO}_{3}^{-}$solution. When grown in $5 \mathrm{mM} \mathrm{NH}_{4} \mathrm{NO}_{3}$, OsNPF7.2-RNAi
29-5 line showed decreased fresh weight, which did not reach a statistical significance (Figure 7A). For the whole plant length, in $0.5 \mathrm{mM} \mathrm{NO}_{3}^{-}$solution, only OsNPF7.2-RNAi plants showed decreased length, while OsNPF7.2-RNAi and osnpf7.2-2 mutant showed decreased length in $10 \mathrm{mM} \mathrm{NO}_{3}^{-}$solution. When grown in $5 \mathrm{mM} \mathrm{NH}_{4} \mathrm{NO}_{3}$, only the OsNPF7.2-RNAi 29-5 line showed a statistically significant decreased length (Figure 7B). Biomass data was consistent with the growth data on $1 / 2 \mathrm{MS}$ medium (Figure 6), though the length did not have obvious differences during the later stage in hydroponic experiments. Above all, the data from OsNPF7.2-RNAi further verify that knock-down of OsNPF7.2 retards rice growth in high nitrate. However, knockdown of OsNPF7.2 did not change the content of $\mathrm{N}$ or nitrate in root and shoot, and the nitrate concentration in xylem sap (Supplementary Figure S5), indicating that OsNPF7.2 is not involved in long-distance allocation of nitrate.

\section{DISCUSSION}

Our data showed that OsNPF7.2 displayed the capacity for nitrate uptake when expressed in Xenopus oocytes and OsNPF7.2 was mainly localized on the membrane of large and small vacuoles. The expression analysis indicated OsNPF7.2 was expressed mainly in elongation and maturation zone of roots. The knock-down of OsNPF7.2 affected rice growth under high concentrations of nitrate; however, altered expression of OsNPF7.2 did not affect the nitrate content of roots and shoots, or translocation of nitrate from roots to shoots. These results suggest that OsNPF7.2 may play a role in the temporary storage or usage of nitrate in the tonoplast of the root elongation and maturation zone.

Most of the NPF members were found to be localized on the plasma membrane and only AtNPF8.3 (PTR2/NTR1), AtNPF8.4 (PTR4) and AtNPF8.5 (PTR6) were found on the tonoplast (Weichert et al., 2012). It is proposed that the motif $\left([\mathrm{D} / \mathrm{E}] \mathrm{X}_{3-5} \mathrm{~L}[\mathrm{~L} / \mathrm{I}]\right)$ in the cytosolic $\mathrm{N}$-terminal region is required for tonoplast localization of NPF proteins, and the loop between the transmembrane domain 6 and 7 is required for the plasma membrane localization (Komarova et al., 2012). OsNPF7.2 has an $\mathrm{EX}_{6} \mathrm{LL}$ motif in the N-terminal region (Supplementary Figure $\mathrm{S} 3 \mathrm{~A})$. The transient expression of OsNPF7.2 in rice protoplasts showed that it was mainly localized on the large (lytic) vacuolar membrane, and some small vacuolar membrane (Figure 3; Supplementary Figure S2). Plant cells are considered to possess functionally different types of vacuoles in a same cell. For example, both protein storage and lytic vacuoles (LV) have been characterized at root meristems of barley and pea seedlings (Olbrich et al., 2007). The protein storage vacuoles (PSV) were shown as small vacuoles in root elongating cells (Fluckiger et al., 2003). Another type of vacuole storing vegetative storage proteins (VSPs) was also identified as small vacuoles within the cytoplasm (Jauh et al., 1998). Spherical structures were observed within the lumen of LVs in rapidly expanding young cotyledons cells of Arabidopsis (Saito et al., 2002). The structures were undefined and emitted strong fluorescence than LVs in $\gamma$-TIP: GPF line. $\gamma$-TIP marks not only LV, but also PSVs and VSPs (Jauh et al., 1999). 
A

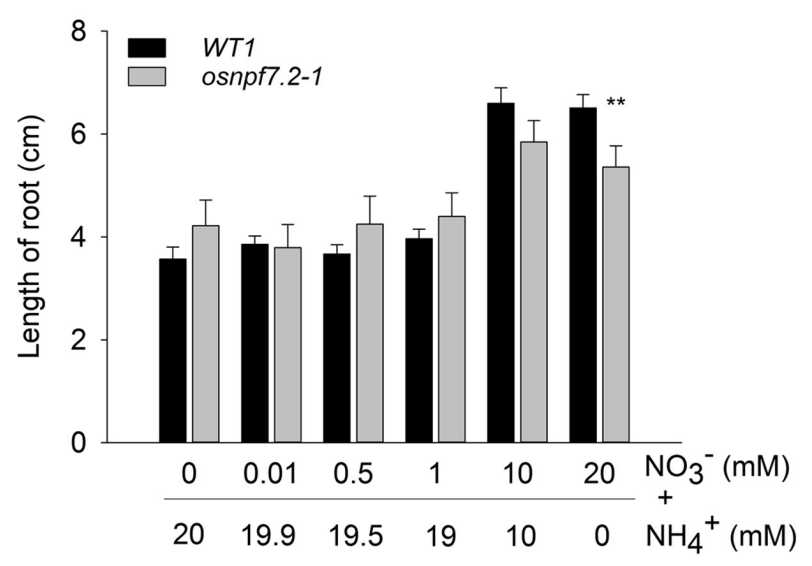

B

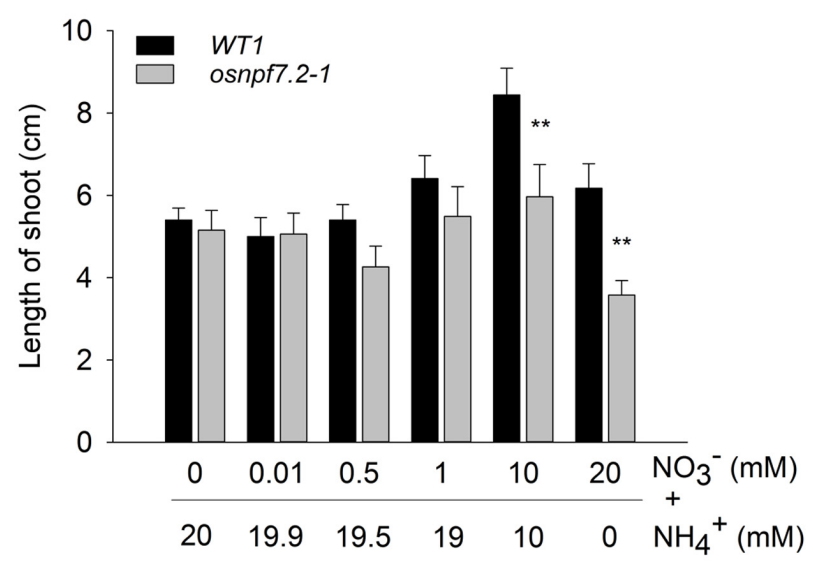

C
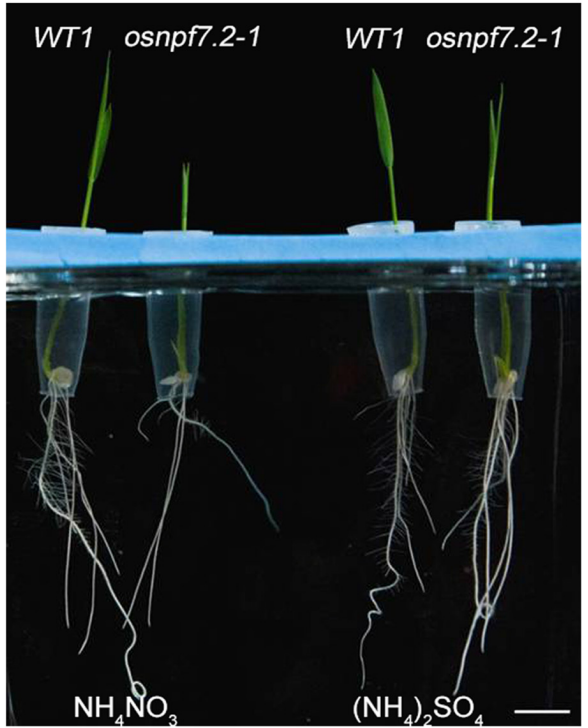

D

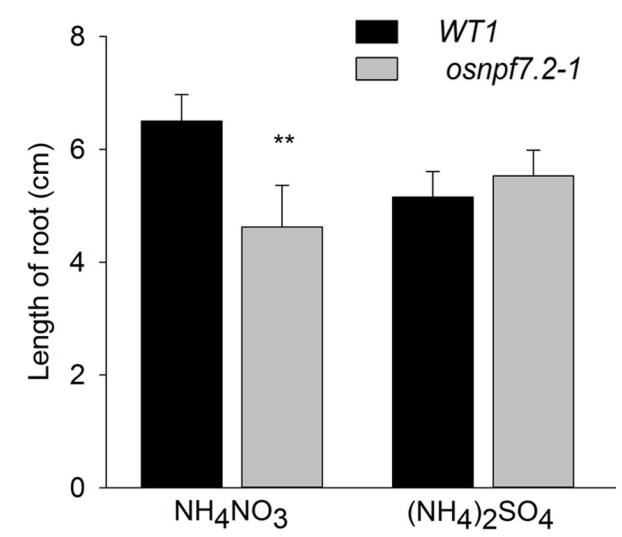

E

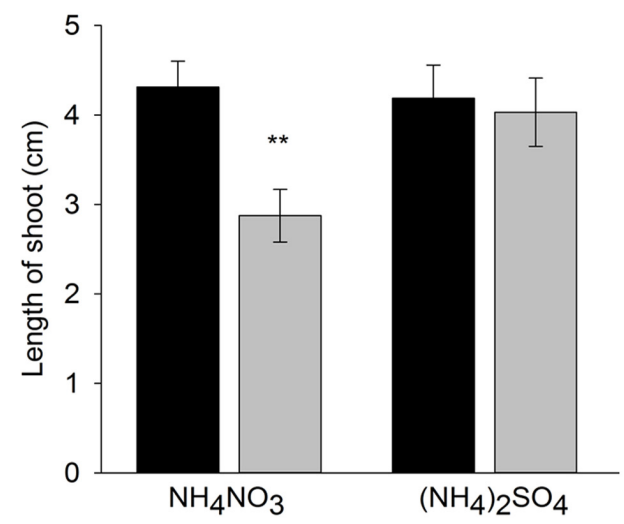

FIGURE 6 | osnpf7.2-1 shows retardant growth under high concentrations of nitrate. (A,B) Root and shoot length of osnpf7.2-1 and wild type plants (ZH11). Wild type and mutant plants grew on $1 / 2 \mathrm{MS}$ medium containing various concentration of $\mathrm{KNO}_{3}$ for $7 \mathrm{~d}$. Ammonium was used to maintain the total $\mathrm{N}$ concentrations in the medium. (C-E) Root and shoot length of osnpf7.2-1 and wild type plants in $10 \mathrm{mM} \mathrm{NH}_{4} \mathrm{NO}_{3}$ and $\left(\mathrm{NH}_{4}\right)_{2} \mathrm{SO}_{4}$. Plants were grown on $1 / 2 \mathrm{MS}$ medium containing $\mathrm{NH}_{4} \mathrm{NO}_{3}$ or $\left(\mathrm{NH}_{4}\right)_{2} \mathrm{SO}_{4}$ as $\mathrm{N}$ source for 7 days. Bar $=1 \mathrm{~cm}$ in (C). For all the subfigures, data represent means of 16 samples and SE. Two independent experiments showed same result. Asterisks indicate significant differences $(P<0.01)$ between osnpf7.2-1 and wild type plants $(\mathrm{ZH} 11)$ by $t$-test. 

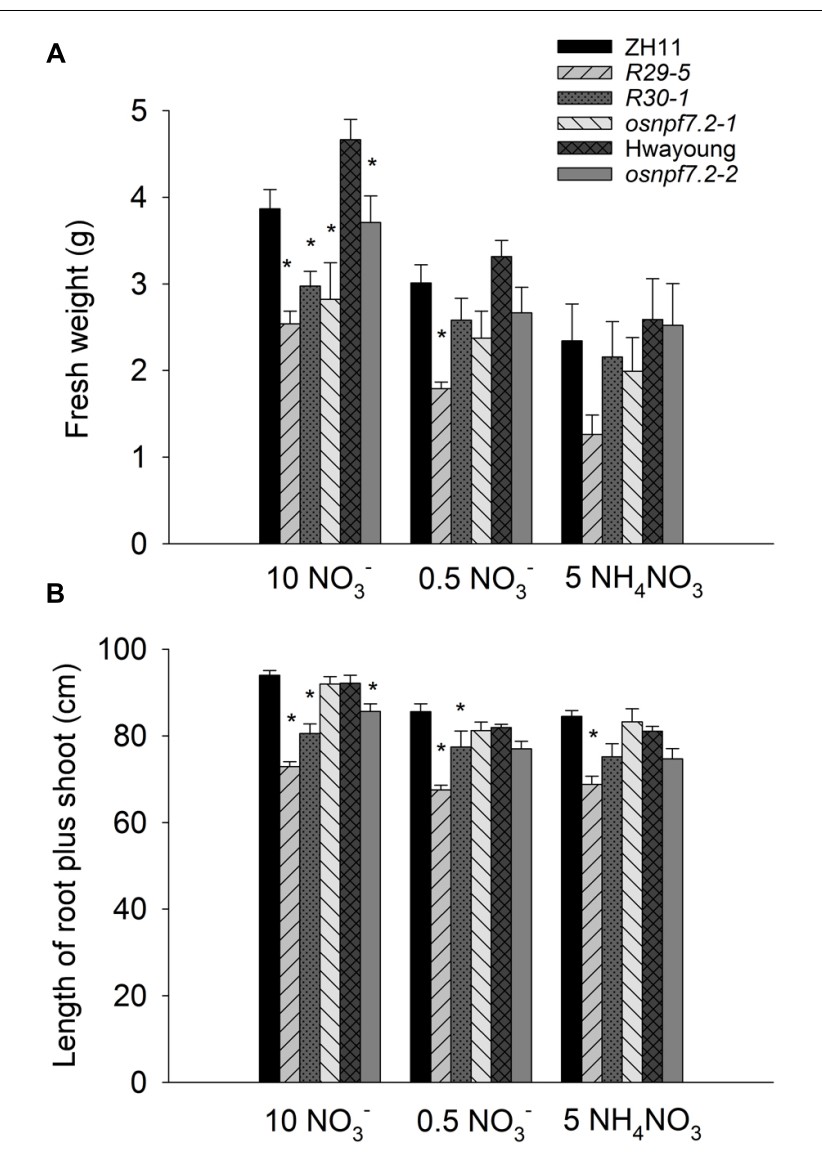

FIGURE 7 | OsNPF7.2-RNAi plants show retardant growth compared with the wild type plants in hydroponic solution. (A) Fresh weight per plant. (B) Length of the whole plants. Plants grew in IRRI solution for 5 weeks, then grew in IRRI solution containing $5 \mathrm{mM} \mathrm{Ca}\left(\mathrm{NO}_{3}\right)_{2}\left(10 \mathrm{NO}_{3}^{-}\right), 0.25 \mathrm{mM}$ $\mathrm{Ca}\left(\mathrm{NO}_{3}\right)_{2}\left(0.5 \mathrm{NO}_{3}^{-}\right)$or $5 \mathrm{mM} \mathrm{NH}_{4} \mathrm{NO}_{3}\left(5 \mathrm{NH}_{4} \mathrm{NO}_{3}\right)$ as $\mathrm{N}$ source for 3 weeks. The wild type of the RNAi lines (R29-5 and R30-1) and osnpf7.2-1 is Z H11. The wild type of osnpf7.2-2 is Hwayoung. Data represent means of 10 samples and SE. Two independent experiments showed same result. Asterisks upon the bars indicate significant differences $(P<0.05)$ between the transgenic line with their corresponding wild type plants in the LSD-test following one-way ANOVA.

Thus the partial co-localization of OsNPF7.2 with $\gamma$-TIP indicates that OsNPF7.2 may be localized not only on the known types of vacuolar membrane, but also other types of vacuolar structures.

OsNPF7.2 failed to take up the dipeptide Pro-Leu when expressed in ptr2 yeast mutant (Supplementary Figure S6). Although the substrates for NPF proteins are diverse, many NPFs investigated are able to transport nitrate. The heterogeneous expression in Xenopus oocytes showed that OsNPF7.2 could mediate the uptake of nitrate (Figure 4), but not as strongly as AtNPF6.3. Hechenberger et al. (1996) suggested that the heterologous expression of CLC proteins and their electrophysiological detection is mainly limited by their localization to the plasma membrane (Hechenberger et al., 1996). The OsNPF7.2 showed tonoplast localization (Figure 3) in rice, this might be the reason that it was not well targeted to the plasma membrane in Xenopus oocytes. However, our attempt to alter its localization for better targeting into the plasma membrane was not successful (Supplementary Figure S3). Changing the $\mathrm{EX}_{6} \mathrm{LL}$ motif in the $\mathrm{N}$-terminal region to $\mathrm{EX}_{6} \mathrm{AA}$ or deleting the LL had no effect on the uptake activity in Xenopus oocytes. That indicates that the full-length OsNPF7.2 might be localized on plasma membrane in Xenopus oocytes. Taken together with the lower accumulation of ${ }^{15} \mathrm{NO}_{3}^{-}$in Xenopus oocytes of the other two rice NPFs (OsNPF6.5 and OsNPF2.2) than negative control, suggests there might be other possible reasons. An alternative explanation for the weak transport activity in Xenopus oocytes might be that the codons of rice are not optimized for Xenopus oocytes (Feng et al., 2013). High GC content of rice NPF genes might affect their expression level in Xenopus oocytes. OsNPF2.4 had been optimized for oocytes and showed a better accumulation of nitrate when expressed in Xenopus oocytes (Xia et al., 2015).

It has been shown that $53 \%$ of nitrate absorbed from the rhizosphere could be directed into assimilation and vacuolar storage in the roots, and only $37 \%$ was translocated to the shoot (Kronzucker et al., 2000). This shows that most nitrate is assimilated in the root or temporarily stored in root vacuoles. OsNPF7.2 is mainly expressed in the elongation and maturation zones of the root (Figure 1) and encodes a protein that is localized on the tonoplast (Figure 3). However, the osnpf7.2 mutants did not show defective translocation of nitrate to the shoot when compared with the wild type (Supplementary Figure S5). This implies that OsNPF7.2 may play a role in intracellular nitrate homeostasis. The nitrate concentration inside the vacuole of rice can reach up to a $40 \mathrm{mM}$ level (Fan et al., 2007). This suggests that rice plants may require low affinity NRTs for export and import of nitrate to the vacuole. OsNPF7.2 may be involved in such a process. The $\mathrm{pH}$ of cytoplasm is about 7.0 to 8.0 , OsNPF7.2 did not exhibit a large difference in the nitrate uptake between $\mathrm{pH}$ 5.5 and pH 7.5 (Figure 4A). This suggests that OsNPF7.2 may be involved in import of nitrate to the tonoplast in plants. Although the concentrations of nitrate in the cytosol in plant are likely to be lower than the $10 \mathrm{mM}$ used in the oocyte experiments (Figure 4), they are reported to be in the low-affinity ( $\mathrm{mM})$, but not highaffinity ( $\mu \mathrm{M})$ range (Miller and Smith, 1996). In rice, OsNPF7.2 may be functionally orthologous to AtCLCa, a vacuolar NRT in Arabidopsis (De Angeli et al., 2006). However, AtCLCa is an antiporter, but NPFs are symporters. This may also suggest that OsNPF7.2 transports nitrate out of vacuoles, considering the more protons in vacuoles. Due to lack of experimental data, it is difficult to conclude whether OsNPF7.2 functions in nitrate storage into the vacuole or remobilization out of the vacuole but in oocytes no efflux activity was detected.

Distinctive from the cell type-specific tissue localization of Arabidopsis NPFs, rice NPFs showed a broader localization. For example, transcripts of AtNPF6.3 accumulated primarily in the epidermal tissue in newly differentiated cells, mostly in the cortex or endodermis of mature parts of the root (Huang et al., 1996). However, rice OsNPF6.5/OsNRT1.1B was expressed in a wider range of cell types including root hairs, epidermis and vascular tissues (Hu et al., 2015). Two Arabidopsis NPF7 subfamily members AtNPF7.3 and AtNPF7.2 were expressed in the root pericycle cells close to the xylem (Lin et al., 2008) and in 
xylem parenchyma cells ( $\mathrm{Li}$ et al., 2010), respectively; while rice OsNPF7.2 was expressed in the cortex and the stele (Figure 2). This indicates that the OsNPF7.2 might play a different role in the rice root from AtNPF7.3 and AtNPF7.2.

Under high nitrate supply, the OsNPF7.2 knock-down plants showed retarded growth compared with their wild type (Figure 6), and high nitrate induced expression of OsNPF7.2. Though the control $\mathrm{KCl}$ treatment also induced expression of OsNPF7.2 by 5 fold, the $10 \mathrm{mM} \mathrm{KNO}_{3}$ induced the expression of OsNPF7.2 by 18 fold. This implies that the $\mathrm{K}$ or $\mathrm{Cl}$ might contribute to the five-fold induction, but does not influence the conclusion that there is nitrate induction of OsNPF7.2. However, knock-down of OsNPF7.2 did not cause a severe phenotype on growth in high nitrate and did not a cause distinctive phenotype in low nitrate except for the RNAi line R29-5. The line R29-5 had two T-DNA inserts, therefore it could not be excluded that the double insertion sites affected its growth. We hypothesize that the weak phenotype of knock-down OsNPF7.2 plants may be due to two reasons: (1) the expression of OsNPF7.2 was not entirely suppressed in the knock-down plants (Figure 5); (2) there are two closely related homologous genes (OsNPF7.3 and OsNPF7.4) (Léran et al., 2014) of OsNPF7.2 in rice and there may be some redundancy.

Curiously for a vacuolar transporter the tissue nitrate content and nitrate translocation did not show differences between knock-down OsNPF7.2 plants and wild type plants (Supplementary Figure S5). It could also be that nitrate might not be the sole substrate of OsNPF7.2, which can also transport other metabolites or hormones as suggested by the data in yeast and plants for many other NPF members. Although many members of the NPF showed peptide or nitrate transport activity, some members in this family transport neither peptides nor nitrate. It seems that only a limited number of members transport peptides or nitrate in the Arabidopsis NPFs (Leran et al., 2015). The yeast ptr2 mutant Y06009 had been used to screen 26 NPFs for the dipeptide Leu-Leu transport activity. Only two members (AtNPF8.1 and AtNPF8.3) previously reported as peptide transporters could be screened using this assay (Leran et al., 2015). Xenopus oocytes were also used for the nitrate transport screening. Their results revealed that a few previously investigated NPFs were confirmed to be able to transport nitrate, but at least two proteins that mediated nitrate influx into oocytes reported in previous studies were not confirmed in this screening.

\section{REFERENCES}

Chiba, Y., Shimizu, T., Miyakawa, S., Kanno, Y., Koshiba, T., Kamiya, Y., et al. (2015). Identification of Arabidopsis thaliana NRT1/PTR FAMILY (NPF) proteins capable of transporting plant hormones. J. Plant Res. 128, 679-686. doi: 10.1007/s10265-015-0710-2

Chopin, F., Orsel, M., Dorbe, M. F., Chardon, F., Truong, H. N., Miller, A. J., et al. (2007). The Arabidopsis ATNRT2.7 nitrate transporter controls nitrate content in seeds. Plant Cell 19, 1590-1602. doi: 10.1105/tpc.107.050542

Cleaver, O. B., Patterson, K. D., and Krieg, P. A. (1996). Overexpression of the tinman-related genes XNkx-2.5 and XNkx-2.3 in Xenopus embryos results in myocardial hyperplasia. Development 122, 3549-3556.

De Angeli, A., Monachello, D., Ephritikhine, G., Frachisse, J. M., Thomine, S., Gambale, F., et al. (2006). The nitrate/proton antiporter AtCLCa mediates
They are AtNPF2.13 (NRT1.7) (Fan et al., 2009) and AtNPF4.6 (NRT1.2) (Huang et al., 1999). The NPF family proteins have been showed to transport several different substrates. Some NPF transporters even had the ability to transport both nitrate and hormones (Krouk et al., 2010; Kanno et al., 2012; Léran et al., 2014). However, three homologous genes (AtNPF7.1, AtNPF7.2, and AtNPF7.3) of OsNPF7.2 did not show transport activity for ABA, GA, and JA-Ile (Chiba et al., 2015). No other members from subfamily 7 of the NFP family have been characterized in other plants. So, more systematic work is required to identify other potential substrates of OsNPF7.2, and transportomics (Krumpochova et al., 2012) may be a very useful solution for this problem in future studies.

\section{AUTHOR CONTRIBUTIONS}

MZ designed the research. RH, DQ, YC, and XP performed the experiments. RH, and DQ carried out vector construct, transgene plant generation, physiology experiments, subcellular localization, yeast assay and expression analysis. YC and XP designed and carried out Xenopus oocytes uptake measurement. $\mathrm{MZ}$ and RH drafted the manuscript. YC, AM, and XF revised the manuscript. All authors approved the manuscript.

\section{ACKNOWLEDGMENTS}

This work was supported by Guangdong Science and Technology Department of China (grant nos. 2015B020231009 and S2013020012830), Guangdong Agriculture Department of China (grant no. 2014492), and the National Natural Science Foundation of China (grant no. 31371604/31272240). YC and $\mathrm{AM}$ are supported by grant funding (BB/JJ004553/1 and BB/L010305/1) from the BBSRC and the John Innes Foundation. $\mathrm{XF}$ are supported by The Jiangsu Science Fund for Distinguished Young Scholars (BK20160030).

\section{SUPPLEMENTARY MATERIAL}

The Supplementary Material for this article can be found online at: http://journal.frontiersin.org/article/10.3389/fpls.2016.01529

nitrate accumulation in plant vacuoles. Nature 442, 939-942. doi: 10.1038 /nature05013

Fan, S. C., Lin, C. S., Hsu, P. K., Lin, S. H., and Tsay, Y. F. (2009). The Arabidopsis nitrate transporter NRT1.7, expressed in phloem, is responsible for source-to-sink remobilization of nitrate. Plant Cell 21, 2750-2761. doi: 10.1105/tpc.109.067603

Fan, X., Jia, L., Li, Y., Smith, S. J., Miller, A. J., and Shen, Q. (2007). Comparing nitrate storage and remobilization in two rice cultivars that differ in their nitrogen use efficiency. J. Exp. Bot. 58, 1729-1740. doi: 10.1093/jxb/ erm033

Fang, Z., Xia, K., Yang, X., Grotemeyer, M. S., Meier, S., Rentsch, D., et al. (2013). Altered expression of the PTR/NRT1 homologue OsPTR9 affects nitrogen utilization efficiency, growth and grain yield in rice. Plant Biotechnol. J. 11, 446-458. doi: 10.1111/pbi.12031 
Feng, H. M., Xia, X. D., Fan, X. R., Xu, G. H., and Miller, A. J. (2013). Optimizing plant transporter expression in Xenopus oocytes. Plant Methods 9:48. doi: 10.1186/1746-4811-9-48

Fluckiger, R., De Caroli, M., Piro, G., Dalessandro, G., Neuhaus, J. M., and Di Sansebastiano, G. P. (2003). Vacuolar system distribution in Arabidopsis tissues, visualized using GFP fusion proteins. J. Exp. Bot. 54, 1577-1584. doi: 10.1093/jxb/erg160

Hechenberger, M., Schwappach, B., Fischer, W. N., Frommer, W. B., Jentsch, T. J., and Steinmeyer, K. (1996). A family of putative chloride channels from Arabidopsis and functional complementation of a yeast strain with a CLC gene disruption. J. Biol. Chem. 271, 33632-33638. doi: 10.1074/jbc.271.52.33632

Hiei, Y., Komari, T., and Kubo, T. (1997). Transformation of rice mediated by Agrobacterium tumefaciens. Plant Mol. Biol. 35, 205-218. doi: 10.1023/a:1005847615493

Hirochika, H. (2001). Contribution of the Tos17 retrotransposon to rice functional genomics. Curr. Opin. Plant Biol. 4, 118-122. doi: 10.1016/s13695266(00)00146-1

Ho, C. H., Lin, S. H., Hu, H. C., and Tsay, Y. F. (2009). CHL1 functions as a nitrate sensor in plants. Cell 138, 1184-1194. doi: 10.1016/j.cell.2009.07.004

Hu, B., Wang, W., Ou, S., Tang, J., Li, H., Che, R., et al. (2015). Variation in NRT1.1B contributes to nitrate-use divergence between rice subspecies. Nat. Genet. 47, 834-878. doi: 10.1038/ng.3337

Huang, N. C., Chiang, C. S., Crawford, N. M., and Tsay, Y. F. (1996). CHL1 encodes a component of the low-affinity nitrate uptake system in Arabidopsis and shows cell type-specific expression in roots. Plant Cell 8, 2183-2191. doi: 10.1105/tpc.8.12.2183

Huang, N. C., Liu, K. H., Lo, H. J., and Tsay, Y. F. (1999). Cloning and functional characterization of an Arabidopsis nitrate transporter gene that encodes a constitutive component of low-affinity uptake. Plant Cell 11, 1381-1392. doi: 10.1105/tpc.11.8.1381

Isayenkov, S., Isner, J.-C., and Maathuis, F. J. M. (2011). Rice two-pore K+ channels are expressed in different types of vacuoles. Plant Cell 23, 756-768. doi: $10.1105 /$ tpc. 110.081463

Jain, M., Nijhawan, A., Tyagi, A. K., and Khurana, J. P. (2006). Validation of housekeeping genes as internal control for studying gene expression in rice by quantitative real-time PCR. Biochem. Biophys. Res. Commun. 345, 646-651. doi: 10.1016/j.bbrc.2006.04.140

Jauh, G. Y., Fischer, A. M., Grimes, H. D., Ryan, C. A., and Rogers, J. C. (1998). delta-Tonoplast intrinsic protein defines unique plant vacuole functions. Proc. Natl. Acad. Sci. U.S.A. 95, 12995-12999. doi: 10.1073/pnas.95.22.12995

Jauh, G. Y., Phillips, T. E., and Rogers, J. C. (1999). Tonoplast intrinsic protein isoforms as markers for vacuolar functions. Plant Cell 11, 1867-1882. doi: 10.1105/tpc.11.10.1867

Jeong, D. H., An, S., Park, S., Kang, H. G., Park, G. G., Kim, S. R., et al. (2006). Generation of a flanking sequence-tag database for activation-tagging lines in japonica rice. Plant J. 45, 123-132. doi: 10.1111/j.1365-313X.2005.02610.x

Kanno, Y., Hanada, A., Chiba, Y., Ichikawa, T., Nakazawa, M., Matsui, M., et al. (2012). Identification of an abscisic acid transporter by functional screening using the receptor complex as a sensor. Proc. Natl. Acad. Sci. U.S.A. 109, 9653-9658. doi: 10.1073/pnas.1203567109

Komarova, N. Y., Meier, S., Meier, A., Grotemeyer, M. S., and Rentsch, D. (2012). Determinants for Arabidopsis peptide transporter targeting to the tonoplast or plasma membrane. Traffic 13, 1090-1105. doi: 10.1111/j.16000854.2012.01370.x

Kronzucker, H. J., Glass, A. D. M., Siddiqi, M. Y., and Kirk, G. J. D. (2000). Comparative kinetic analysis of ammonium and nitrate acquisition by tropical lowland rice: implications for rice cultivation and yield potential. New Phytol. 145, 471-476. doi: 10.1046/j.1469-8137.2000.00606.x

Kronzucker, H. J., Siddiqi, M. Y., Glass, A. D. M., and Kirk, G. J. D. (1999). Nitrateammonium synergism in rice. A subcellular flux analysis. Plant Physiol. 119, 1041-1045. doi: 10.1104/pp.119.3.1041

Krouk, G., Lacombe, B., Bielach, A., Perrine-Walker, F., Malinska, K., Mounier, E., et al. (2010). Nitrate-regulated auxin transport by NRT1.1 defines a mechanism for nutrient sensing in plants. Dev. Cell 18, 927-937. doi: 10.1016/j.devcel.2010.05.008

Krumpochova, P., Sapthu, S., Brouwers, J. F., De Haas, M., De Vos, R., Borst, P., et al. (2012). Transportomics: screening for substrates of ABC transporters in body fluids using vesicular transport assays. FASEB J. 26, 738-747. doi: 10.1096/fj.11-195743

Lassaletta, L., Billen, G., Grizzetti, B., Anglade, J., and Garnier, J. (2014). 50 year trends in nitrogen use efficiency of world cropping systems: the relationship between yield and nitrogen input to cropland. Environ. Res. Lett. 9:105011. doi: 10.1088/1748-9326/9/10/105011

Leran, S., Garg, B., Boursiac, Y., Corratge-Faillie, C., Brachet, C., Tillard, P., et al. (2015). AtNPF5.5, a nitrate transporter affecting nitrogen accumulation in Arabidopsis embryo. Sci. Rep. 5:7962. doi: 10.1038/srep07962

Leran, S., Munos, S., Brachet, C., Tillard, P., Gojon, A., and Lacombe, B. (2013). Arabidopsis NRT1.1 is a bidirectional transporter involved in root-to-shoot nitrate translocation. Mol. Plant 6, 1984-1987. doi: 10.1093/mp/sst068

Léran, S., Varala, K., Boyer, J.-C., Chiurazzi, M., Crawford, N., DanielVedele, F., et al. (2014). A unified nomenclature of NITRATE TRANSPORTER 1/PEPTIDE TRANSPORTER family members in plants. Trends Plant Sci. 19, 5-9. doi: 10.1016/j.tplants.2013.08.008

Li, J. Y., Fu, Y. L., Pike, S. M., Bao, J., Tian, W., Zhang, Y., et al. (2010). The Arabidopsis nitrate transporter NRT1.8 functions in nitrate removal from the xylem sap and mediates cadmium tolerance. Plant Cell 22, 1633-1646. doi: 10.1105/tpc.110.075242

Li, S., Qian, Q., Fu, Z., Zeng, D., Meng, X., Kyozuka, J., et al. (2009). Short panicle1 encodes a putative PTR family transporter and determines rice panicle size. Plant J. 58, 592-605. doi: 10.1111/j.1365-313X.2009.03799.x

Li, X., Fan, T., Song, J., Sun, W., Xia, K., Liao, J., et al. (2014). Functional conservation and divergence of four ginger AP1/AGL9 MADS-Box genes revealed by analysis of their expression and protein-protein interaction, and ectopic expression of AhFUL gene in Arabidopsis. PLoS ONE 9:e114134. doi: 10.1371/journal.pone.0114134

Li, Y., Ouyang, J., Wang, Y. Y., Hu, R., Xia, K., Duan, J., et al. (2015). Disruption of the rice nitrate transporter OsNPF2.2 hinders root-to-shoot nitrate transport and vascular development. Sci. Rep. 5:9635. doi: 10.1038/ srep09635

Lin, C. M., Koh, S., Stacey, G., Yu, S. M., Lin, T. Y., and Tsay, Y. F. (2000). Cloning and functional characterization of a constitutively expressed nitrate transporter gene, OsNRT1, from rice. Plant Physiol. 122, 379-388. doi: 10.1104/pp.122.2.379

Lin, S. H., Kuo, H. F., Canivenc, G., Lin, C. S., Lepetit, M., Hsu, P. K., et al. (2008). Mutation of the Arabidopsis NRT1.5 nitrate transporter causes defective root-to-shoot nitrate transport. Plant Cell 20, 2514-2528. doi: $10.1105 /$ tpc.108.060244

Liu, K. H., Huang, C. Y., and Tsay, Y. F. (1999). CHL1 is a dual-affinity nitrate transporter of Arabidopsis involved in multiple phases of nitrate uptake. Plant Cell 11, 865-874. doi: 10.2307/3870820

Martinoia, E., Heck, U., and Wiemken, A. (1981). Vacuoles as storage compartments for nitrate in barley leaves. Nature 289, 292-294. doi: $10.1038 / 289292 \mathrm{a} 0$

Miller, A. J., and Smith, S. J. (1996). Nitrate transport and compartmentation in cereal root cells. J. Exp. Bot. 47, 843-854. doi: 10.1093/jxb/47.7.843

Murashige, T., and Skoog, F. (1962). A revised medium for rapid growth and bio assays with tobacco tissue cultures. Physiol. Plant. 15, 473-497. doi: 10.1111/j.1399-3054.1962.tb08052.x

Nelson, B. K., Cai, X., and Nebenfuehr, A. (2007). A multicolored set of in vivo organelle markers for co-localization studies in Arabidopsis and other plants. Plant J. 51, 1126-1136. doi: 10.1111/j.1365-313X.2007.03212.x

Nour-Eldin, H. H., Andersen, T. G., Burow, M., Madsen, S. R., Jørgensen, M. E., Olsen, C. E., et al. (2012). NRT/PTR transporters are essential for translocation of glucosinolate defence compounds to seeds. Nature 488, 531-534. doi: 10.1038 /nature 11285

Olbrich, A., Hillmer, S., Hinz, G., Oliviusson, P., and Robinson, D. G. (2007) Newly formed vacuoles in root meristems of barley and pea seedlings have characteristics of both protein storage and lytic vacuoles. Plant Physiol. 145, 1383-1394. doi: 10.1104/pp.107.108985

Parker, J. L., and Newstead, S. (2014). Molecular basis of nitrate uptake by the plant nitrate transporter NRT1.1. Nature 507, 68-72. doi: 10.1038/ nature 13116

Pike, S., Gao, F., Kim, M. J., Kim, S. H., Schachtman, D. P., and Gassmann, W. (2014). Members of the NPF3 transporter subfamily encode pathogen-inducible 
nitrate/nitrite transporters in Grapevine and Arabidopsis. Plant Cell Physiol. 55, 162-170. doi: 10.1093/pcp/pct167

Riveras, E., Alvarez, J. M., Vidal, E. A., Oses, C., Vega, A., and Gutierrez, R. A. (2015). The calcium ion is a second messenger in the nitrate signaling pathway of Arabidopsis. Plant Physiol. 169, 1397-1404. doi: 10.1104/pp.15.00961

Saito, C., Ueda, T., Abe, H., Wada, Y., Kuroiwa, T., Hisada, A., et al. (2002). A complex and mobile structure forms a distinct subregion within the continuous vacuolar membrane in young cotyledons of Arabidopsis. Plant J. 29, 245-255. doi: 10.1046/j.0960-7412.2001.01189.x

Sugiura, M., Georgescu, M. N., and Takahashi, M. (2007). A nitrite transporter associated with nitrite uptake by higher plant chloroplasts. Plant Cell Physiol. 48, 1022-1035. doi: 10.1093/pcp/pcm073

Sun, J., Bankston, J. R., Payandeh, J., Hinds, T. R., Zagotta, W. N., and Zheng, N. (2014). Crystal structure of the plant dual-affinity nitrate transporter NRT1.1. Nature 507, 73-77. doi: 10.1038/nature13074

Tal, I., Zhang, Y., Jorgensen, M. E., Pisanty, O., Barbosa, I. C. R., Zourelidou, M., et al. (2016). The Arabidopsis NPF3 protein is a GA transporter. Nat. Commun. 7:11486. doi: $10.1038 /$ ncomms 11486

Tegeder, M., and Rentsch, D. (2010). Uptake and partitioning of amino acids and peptides. Mol. Plant 3, 997-1011. doi: 10.1093/mp/ssq047

Tong, Y., Zhou, J. J., Li, Z. S., and Miller, A. J. (2005). A two-component highaffinity nitrate uptake system in barley. Plant J. 41, 442-450. doi: 10.1111/j.1365313X.2004.02310.x

Tsay, Y. F., Schroeder, J. I., Feldmann, K. A., and Crawford, N. M. (1993). The herbicide sensitivity gene CHL1 of Arabidopsis encodes a nitrateinducible nitrate transporter. Cell 72, 705-713. doi: 10.1016/0092-8674(93) 90399-B

van der Leij, M., Smith, S. J., and Miller, A. J. (1998). Remobilisation of vacuolar stored nitrate in barley root cells. Planta 205, 64-72. doi: 10.1007/s004250050297

Wang, M., Chen, C., Xu, Y. Y., Jiang, R. X., Han, Y., Xu, Z. H., et al. (2004). A practical vector for efficient knockdown of gene expression in rice (Oryza sativa L.). Plant Mol. Biol. Rep. 22, 409-417. doi: 10.1007/BF02772683

Weichert, A., Brinkmann, C., Komarova, N. Y., Dietrich, D., Thor, K., Meier, S., et al. (2012). AtPTR4 and AtPTR6 are differentially expressed, tonoplast-localized members of the peptide transporter/nitrate transporter 1 (PTR/NRT1) family. Planta 235, 311-323. doi: 10.1007/s00425-0111508-7

Xia, X., Fan, X., Wei, J., Feng, H., Qu, H., Xie, D., et al. (2015). Rice nitrate transporter OsNPF2.4 functions in low-affinity acquisition and long-distance transport. J. Exp. Bot. 66, 317-331. doi: 10.1093/jxb/eru425

Xu, G. H., Fan, X. R., and Miller, A. J. (2012). "Plant nitrogen assimilation and use efficiency," in Annual Review of Plant Biology, Vol. 63, ed. S. S. Merchant (Palo Alto, CA: Annual Reviews), 153-182.

Yoshida, S., Forno, D. A., Cook, J. H., and Gomez, K. A. (eds). (1976). "Routine procedure for growing rice plants in culture solution," in Laboratory Manual for Physiological Studies of Rice (Los Banos: International Rice Research Institute), 61-66.

Zhang, J., Li, C., Wu, C., Xiong, L., Chen, G., Zhang, Q., et al. (2006). RMD: a rice mutant database for functional analysis of the rice genome. Nucleic Acids Res. 34, D745-D748. doi: 10.1093/nar/gkj016

Zhang, Y., Su, J., Duan, S., Ao, Y., Dai, J., Liu, J., et al. (2011). A highly efficient rice green tissue protoplast system for transient gene expression and studying light/chloroplast-related processes. Plant Methods 7:30. doi: 10.1186/17464811-7-30

Zhou, J. J., Theodoulou, F. L., Muldin, I., Ingemarsson, B., and Miller, A. J. (1998). Cloning and functional characterization of a Brassica napus transporter that is able to transport nitrate and histidine. J. Biol. Chem. 273, 12017-12023. doi: $10.1074 /$ jbc.273.20.12017

Conflict of Interest Statement: The authors declare that the research was conducted in the absence of any commercial or financial relationships that could be construed as a potential conflict of interest.

Copyright $\odot 2016 \mathrm{Hu}$, Qiu, Chen, Miller, Fan, Pan and Zhang. This is an open-access article distributed under the terms of the Creative Commons Attribution License $(C C B Y)$. The use, distribution or reproduction in other forums is permitted, provided the original author(s) or licensor are credited and that the original publication in this journal is cited, in accordance with accepted academic practice. No use, distribution or reproduction is permitted which does not comply with these terms. 